\title{
Configurations of Care Work: Paid and Unpaid Elder Care in Italy and the Netherlands
}

\author{
by Miriam Glucksmann and Dawn Lyon \\ University of Essex; University of Essex
}

Sociological Research Online, Volume 11, Issue 2,

< http://uww.socresonline.org.uk/11/2/glucksmann.html>

doi: $10.5153 /$ sro. 1398

Received: 9 Jan 2006 Accepted: 30 Jun 2006 Published: 30 Jun 2006

\begin{abstract}
Most current sociological approaches to work recognise that the same activity may be undertaken within a variety of socio-economic forms - formal or informal, linked with the private market, public state or not-forprofit sectors. This article takes care of the elderly as an exemplary case for probing some of the linkages between paid and unpaid work. We attempt to unravel the interconnections between forms of care work undertaken in different socio-economic conditions in two settings, the Netherlands and Italy. The research is part of a broader programme concerned with differing interconnections and overlaps between work activities. In this article, we are concerned with: 1) how paid and unpaid care work map on to four 'institutional' modes of provision - by the state, family, market, and voluntary sector; and 2) with the configurations that emerge from the combination of different forms of paid and unpaid work undertaken through the different institutions. Despite the centrality of family-based informal care by women in both countries, we argue that the overall configurations of care are in fact quite distinct. In the Netherlands, state-funded care services operate to shape and anchor the centrality of family as the main provider. In this configuration, unpaid familial labour is sustained by voluntary sector state-funded provision. In Italy, by contrast, there is significant recourse to informal market-based services in the form of individual migrant carers, in a context of limited public provision. In this configuration, the state indirectly supports market solutions, sustaining the continuity of family care as an ideal and as a practice.
\end{abstract}

\section{Keywords: Work, Employment, Total Social Organisation of Labour, Care Work, Elder Care, Italy, the Netherlands, Configuration, Gender}

Introduction

1.1 Most current sociological approaches to work recognise that the same activity may be undertaken within a variety of socio-economic forms - formal or informal, linked with the private market, public state or not-for-profit sectors. This form affects not only whether the work is paid or not, but also its social and cultural underpinnings and embeddedness, how it is understood, and its emotional resonances for social actors. However, incorporating and analysing both paid and unpaid forms of the same labour activity within the same research remains a challenge, and doing so comparatively further complicates matters.

1.2 This article takes care of the elderly as an exemplary case for probing some of the linkages between paid and unpaid work. Care is significant as an activity that is simultaneously work and non-work, undertaken for love or money (Graham, 1991), and embedded in or differentiated from other relationships (affection, duty, obligation) to varying degrees. We attempt to unravel the interconnections between forms of care work undertaken in different socio-economic conditions in two settings, the Netherlands and Italy. The research is part of a broader programme concerned with differing interconnections and overlaps between work activities (see Glucksmann, 2006a). ${ }^{[1]}$ A principal aim of this programme is to develop the conceptual framework of the 'total social organisation of labour' originally formulated to address the connections between work undertaken in diverse socio-economic spaces (Glucksmann, 1995, 2000). We are concerned with: 1) how paid and unpaid care work map on to four 'institutional' modes of provision - by the state, family, market and voluntary sector; and 2) the configurations that emerge from the combination of different forms of paid and unpaid work undertaken through the different institutions. ${ }^{[2]}$ We ask whether the respective roles of the state and public services, private sector market services, the voluntary or not-forprofit sector, and the family are separate or inter-dependent. Can distinctive configurations of care work be singled out, and if so what are their principles of variation?

1.3 At face value, elder care provision in Italy and the Netherlands may seem similar, but our research suggests considerable divergence between them. In both countries, family-based informal carers, mostly women, comprise the key carers for the elderly. However, not only do families undertake their tasks in quite different ways, but the relationship between the work of family care and other forms of provision also differs 
markedly. We argue that in the Netherlands, state-funded care services operate to shape and anchor the centrality of family as the main provider. In this configuration, unpaid familial labour is sustained by voluntary sector state-funded provision. In Italy, by contrast, there is significant recourse to informal marketbased services in the form of individual migrant carers, and very limited state provided services, although cash payments by the state indirectly support market solutions. This configuration sustains the continuity of family care as an ideal and a practice (Lyon, 2006).

1.4 Our approach and findings contribute to several strands of sociological thinking. First, to the sociology of work. A dominant feature of the literature on care is the multiplicity of meanings given to it, some writers highlighting emotional connections, and others the labour of care. ${ }^{[3]}$ Our starting point is to consider care as a work activity whatever the employment or other social relations of the context, and regardless of how it cuts across boundaries between socio-economic modes. Conceptualising the labour of care as multidimensional and straddling diverse relations offers a distinctive approach for the sociology of work. Second, we contribute to the literature on care by providing an analytical mapping which foregrounds interconnections between different forms of provision. This has relevance for settings beyond those considered here.

1.5 The discussion is organised as follows. In the next section, we provide a rationale for the countries chosen and elaborate our methodology. We then offer a more detailed portrayal of the organisation of care work in the Netherlands and in Italy. Two analytical sections follow. The first conceptualises interconnections between different forms of care work in the context of existing thinking in the field. The second disentangles certain dimensions of the embeddedness and differentiation of care in different social relationships, discussing care as work, kinship, domestic labour, duty and rights.

\section{The Challenges of Comparative Research}

2.1 Our approach focuses on the specificities of different national settings. Each country can be characterised in terms of the distinctiveness of its configuration of elder care provision between the four putative providers - the state and public services, the private sector market services, the voluntary or notfor-profit sector, and the family - highlighting features that are unique to it. On this basis, the Netherlands is characterised by informal and voluntary work, and Italy by informal work and migrant labour. The exercise of comparing and contrasting in turn illuminates the place of paid and unpaid forms of care work in each country. This approach has been useful to situate the shared dominant features of elder care provision and work in both countries, i.e., informal care, in relation to other forms of provision.

2.2 Our primary research is based on interviews conducted by the authors in spring and summer 2005 with national or international 'experts' on elder care provision in each country, including academics, policymakers and public officials, and voluntary sector workers. Seven interviews were carried out in each country. ${ }^{[4]}$ Questions sought to elicit general understandings of the past, present and future of elder care work (e.g., is there a crisis?); the perceived relative contribution of the state, voluntary sector, private sector, and family to elder care; the variety of meanings attributed to 'care' and 'care work'; and the composition and conditions of the care workforce, how it is gendered and racialised, and whether the work is conducted on a formal or informal, legal or illegal, and paid or unpaid basis. This primary research is complemented by the relevant literature relating to each country, secondary analysis of appropriate statistical and occupational data, and policy and other official documents.

2.3 Why Italy and the Netherlands? These countries are interesting precisely on account of the simultaneous similarity and difference in their respective arrangements for elder care and what these imply for the organisation of paid versus unpaid work. In demographic terms, both Italy and the Netherlands face a similar scenario: an ageing population. In Italy this problem is already acute: one quarter of the population is currently over 60 , and this is expected to rise to more than two in five $(42 \%)$ by 2050 . In the Netherlands, the proportion is lower, at around one fifth (19\%) but expected to rise to one third by 2050 . In both countries the elderly population is clearly differentiated by gender with more women than men surviving into old age: there are 73 men for every 100 women over 60 in Italy, and 77 in the Netherlands (UN, 2002).

2.4 In addition, the availability of carers, both informally (family carers, friends, neighbours) and formally (in professional or non-professional employment) is declining. Several factors contribute to this trend: a lengthening of working life in the post-war period; a decrease in family size and thereby of the number of daughters available in previous generations to care for elderly parents; changing household structures and the demise of extended family in close geographical proximity. At the same time, the increase in women's paid employment has been very significant. In $2004,65.8 \%$ of women in the Netherlands were active in the labour market, and $45.2 \%$ were active in Italy (Eurostat). Thus, the problem of an increasing mismatch between the growing demand for elder care and the diminishing numbers available to supply it is significant in both countries.

\section{The Netherlands: family care, the voluntary sector and the state}

3.1 The provision and organisation of elder care in the Netherlands has undergone considerable change over recent years in the wake of continuing welfare-state retrenchment. In much comparative research, the 
Netherlands is characterised for the significance of the state provision of elder care, especially the high usage of residential facilities, which was the highest in Europe in the 1970s and 1980s (OECD, 1996).

Bettio and Plantenga (2004: 101), for instance, suggest that whereas the family is considered the rightful locus of care for children in the Netherlands, the state is deemed appropriate for the elderly. Knijn (2000) however, draws attention to state attempts since the late 1980s to significantly reduce costs and responsibilities in this field. Compared with many EU countries, notably Italy, the importance of state provision is certainly marked and this is significant both for past provision and as the context for current change. Looking more closely at the direction of change, recent reports and our own interviews indicate a strong move away from institutionalisation, a reduction in state services (which are largely contracted to the voluntary sector), and a strengthening, in policy and practice, of the role of informal family care.

3.2 Informal care for the elderly, known as 'mantelzorg', is at the core of provision, and a defining characteristic of the Dutch system. The term dates from the 1970 s to describe care activity in informal settings. 'Mantelzorg' literally means 'coat' or 'mantle' care, and is a metaphor for being surrounded by warmth and affection. Estimates suggest that more than 2 million, out of a total population of 16.3 million (i.e., at least 12 per cent), are currently engaged in providing informal care, of whom 400,000 provide longterm and intensive care (Nitsche et al., 2004). The majority of informal carers are women, either partners or daughters of the care recipient. Overall, $80 \%$ of care is estimated to be undertaken by the family (Timmermans, 2003), 50\% of whom feel heavily burdened (de Klerk, 2001). In addition to the nuclear family, the extended family, friends, neighbours and volunteers also operate as informal networks of care. In a 2001 survey on informal help, the number of those 'offering help to family members or close acquaintances' with health problems was 3.7 million (Timmermans, 2003: 232). In practice there are class differences in provision, and in working class families more direct care is provided (de Roit, 2004). The lower socioeconomic status of some ethnic minority groups in the Netherlands, notably Turks, means that they are disproportionately located within specific care arrangements.

3.3 Professional and public provision of care increasingly acts as a safety net for those who have no access to an informal solution, where the resilience of social networks of informal care is low, or the need for help is very great. Since the 1980s, reductions in the provision of institutional care have been coupled with more selective processes for identifying those 'needing' residential care, e.g., the very frail elderly (de Roit, 2004: 84), and an expansion of home care services. This means that state provision is made available on the basis of social isolation, as opposed to where there are the highest levels of need by the recipient of care (Timmermans, 2003: 234). The limitations in state support explicitly rely on obligation between kin. Indeed, care assessments involve asking direct questions about who the potential care recipient lives with, where their family is located, and their relationships to neighbours. Backed-up by an extensive system of home care services (Anxo and Fagan, 2005), and popular 'cash for care' arrangements permitting those assessed as entitled to home care to pay informal carers (Yeandle and Ungerson, 2003, Interviews a, c), informal home-based care appears to have the highest priority in official government policy.

3.4 In this context, the key role of state services has shifted away from formal provision to sustaining family care by alleviating pressure on informal carers. The position of informal carers is officially recognised, and government funding to the many voluntary organisations assisting them has expanded. Covering every municipality, these attempt to reduce the strains on family carers through respite care, day centres, homebased visits and out-of-pocket expenses to volunteers. Recent innovations include publicity campaigns to raise the self-awareness of carers, group meetings and advice sessions, social gatherings, trips, and holidays in specially dedicated hotels (Interviews e, $\mathrm{f}, \mathrm{g}, \mathrm{h}$ and documents from Markant). In this respect, carers, rather than care receivers, appear as the prime focus of policy concern and provision, and there is evidence of strong take-up of such support services. ${ }^{[5]}$ However, it is questionable whether all respite arrangements are culturally appropriate. ${ }^{[6]}$ Furthermore, a university course to train 'family care agents' ('mantelzorgmakelaar') began in 2005 as a new initiative to create specialists who manage the interface between informal care and the public and voluntary services, by arranging care services, housing, benefits and information for those in need. ${ }^{[7]}$ It is intended that care agents work on behalf of care seekers or their relatives and local authorities. But it is also anticipated that firms will buy these services on behalf of employees, in an effort to reduce time taken off work for arranging care.

3.5 Although the state has a long history of supporting care, this has taken the form of funding, rather than the actual delivery of services, which traditionally has been contracted to the not-for-profit sector. Originally religious-based voluntary organisations, these are now more varied, but remain extremely active, especially in response to recent policy changes. An increasingly significant feature of the Netherlands is its multiethnic composition. Seventeen per cent of the population are of non-Dutch origin, including nine per cent who are from Turkey, Morocco, the Antilles, Surinam, and Indonesia. As this population ages, and the numbers of labour migrants who remain in the Netherlands post-retirement increase, the population of elder care recipients will include greater ethnic and religious diversity. Whilst informal care is widely believed to be a strong practice amongst the ethnic minority populations in the Netherlands (Interviews $c, f, g$ ), this raises questions for the future about the provision of care through the voluntary sector with its dominant Christian legacy.

3.6 With respect to unpaid work, care given to households other than one's own is close to the highest in EU25: $29.2 \%$ of the population in the Netherlands (working, retired or unemployed) provide care outside 
their own household. This compares to just $11.4 \%$ in Italy. ${ }^{[8]}$ And while $31.4 \%$ of the Dutch are engaged in care-giving activities, $18.2 \%$ of Italians provide informal care. However, interviewees report a decline in volunteering and a shift to older people as volunteers, a development that counter-measures are being sought to arrest (Interview b). The important role of the voluntary sector in orchestrating both paid and unpaid forms of care work and the extent of volunteering emerge as distinctive to care provision in the Netherlands, distinguishing it not only from Italy but also from most EU countries.

3.7 Of those directly employed in personal care through voluntary organisations (including but not exclusively for the elderly), a very high proportion are women (96\% in 2000). Indeed nearly one quarter of all employed women in the Netherlands is concentrated in care occupations. ${ }^{\left[{ }^{[9]}\right.}$ The use of migrant labour, formally or informally, to fill the gap in the supply of elder care is minimal. According to official statistics $98 \%$ of 'personal care and related' employees were of Dutch nationality and our informants confirmed the absence of private or informal buying-in of the services of migrants as carers. ${ }^{[10]}$

3.8 Finally, of particular significance in the Netherlands is the policy and ideological emphasis on 'care independence' (self-reliance) whereby people are responsible for their own care (Sevenhuijsen, 2002: 19). However, the discourse of freedom of choice belies the financial cutbacks which underpin recent changes. The introduction of personal budgets could also be seen in this spirit, despite their popularity, since they displace the burden - and 'freedom' - of organising care onto the recipient, and are offered as an alternative to receiving services from a home care organisation, as is the tone of the Social Support Act which seeks to integrate health and welfare at the local level. Its strong emphasis on citizens' responsibility for their own care and support for independent living imply that state services will be provided only in the absence of informal solutions (Nitsche et al., 2004: 6).

\section{Italy: family care and the informal economy}

4.1 As in the Netherlands, most work of elder care in Italy is carried out informally by family members. Indeed, the long-term care of $83 \%$ of those in need is met by family (and/or friends and neighbours) (Bettio et al., forthcoming). An estimated 2.5 million people, out of a total population of 58.5 million, care for a dependent older relative, the vast majority $(80 \%)$ being women (Polverini et al., 2004: 12-13). Although this represents a considerably lower proportion of the population than in the Netherlands, it rises to $11 \%$ of those over 50 . The majority of persons offering informal care to adult dependent family members do so without recourse to any other form of care.

4.2 If family care remains the dominant mode of provision of elder care, a very significant trend in recent years is the employment of migrant labour for home-based care. Italy has amongst the largest proportion of domestic and personal care workers in Western Europe, most of whom are migrant women, often employed without a regular contract. Between 600 and 700,000 people are estimated to be hired by Italian families in home help care as personal assistants. ${ }^{[11]}$ More than one in ten Italians over $60(10.2 \%)$ make use of private domestic-based care, a figure which rises to $12.4 \%$ for $70-79$ year olds, and $20 \%$ for the over 80 s, evidencing the significance of this form of care work (Bettio et al., forthcoming).

4.3 It is probable that the relatively low cost of employing a migrant worker is a stimulus to the development of this form of care. If the situation of the worker is completely regularised and social security payments are made, then wage costs (for non-residential carers) vary between 1000 (Northern Italy) and 800 (elsewhere) euros per month. With generous pensions and disability allowances, and the payment of an attendance allowance of up to 450 euros per month, this option is within the reach of even lower middle class families. It is considerably more affordable, and appealing, than a residential care home for the elderly relative (Interviews 3, 4). For migrants employed in the formal sector, numbers are regulated by annual quota, with permits strictly tied to employment, making domestic workers highly dependent on the goodwill of their employers. Alongside formal employment, large numbers are employed informally. Women from Eastern Europe often work on a temporary basis, for two to three months at a time, sharing jobs with female family members or friends. This practice, widely referred to as 'pendulum migration', means that they rotate work in Italy (and other EU countries) with periods at 'home', repeatedly returning on tourist visas.

4.4 The relationship between families and migrant carers is mediated in a variety of ways, through private sector agencies and (semi)formal networks, notably connected to the church, the state (local authority lists of registered carers), and informal networks. What is conspicuous is that this is a widespread but not systematised response to care needs: each case is an individual solution. So whilst solutions are often commercial, there is not a strong presence of privatised formal market services.

4.5 The trend towards informal employment of migrants for care work has taken place in a specific political, economic, cultural-social and institutional context. The welfare state is relatively weak, and the supply of private sector alternatives is low. The underground economy operating outside of legal regulation makes it easy for migrants to live and work in shifting relations of legality and illegality. The retrospective orientation of regularisation schemes for those in work but without legal status (five have been introduced since the 1980 s) is considered to have had a powerful impact on migratory practices (Bettio et al., forthcoming; Morris, 2002; Sciortino, 2004; Trifiletti, 1998). 
4.6 Overall then, the picture in Italy is of the predominance of family care with reliance on individual marketbased solutions. The role of the state is very limited in the provision of services. The take-up of residential care is very low, with only around two per cent of old people living in homes (see Polverini et al., 2004) ${ }^{[12]}$ although there is considerable regional variation with much higher usage in the North than the South. Home care reaches as few as three per cent of the elderly (Pesaresi and Gori, 2005). In general, social services simply do not have the resources to satisfy care needs beyond a very restricted number of cases or situations. However, it is also clear that the state does contribute indirectly to the funding of family care through generous pensions, disability allowances and attendance and care allowances, which are completely discretionary. ${ }^{[13]}$ And it facilitates and funds voluntary organisation projects including for elder care around specific tasks, e.g., shopping, and transport. Other agencies in the voluntary sector, notably religious charities, and trade union based organisations also play a significant role.

4.7 The culture of family care remains very powerful, and the family remains the core provider. Although the proportion of multi-generational households has declined, geographical proximity between generations is a common feature of intergenerational care arrangements (see Saraceno and Naldini, 2001). Amongst informal carers, as many as two in five $(42 \%)$ live in the same house as the person to whom they give assistance, and one third (32\%) live very close-by (Quattrini et al., 2003, in Polverini et al., 2004: 17). In contrast to the Netherlands, there is not the rhetoric or onus on self-reliance and autonomy. Instead, concerns are centred around combating isolation and loneliness and sustaining social connections.

\section{Contrasting configurations of care work}

5.1 The organisation of elder care in Italy and the Netherlands provides us with the material for analysing the different socio-economic modes of care work and how these interconnect. The aim now is to map modes of provision onto differing relations of work, in a configurational analysis. It is evident that care work occurs within a range of socio-economic and interpersonal relations, varying nationally and over time between the state, the market, the voluntary/non-profit sector and the family. This section conceptualises and contrast the nexus of relations specific to each country, as the basis for understanding the distribution and interactions between paid and unpaid forms of work.

5.2 Our analytical resources include a number of literatures and models which approach the provision of care in similar terms. However, these focus more squarely on issues of welfare or interpretation of social policies, while our central concern is with care as work, and how the interface of care/work is shaped. Three especially relevant lines of thinking about the relationships between care work in different socio-economic modes are offered by Esping-Andersen, Ungerson and Yeandle, and Mingione.

5.3 The widely known typology of welfare state regimes proposed by Esping-Andersen (1990, 1996, 1999) is based on the connections between state, market and family/household. Whilst fully cognizant of the potential of Esping-Andersen, and the many critical revisions of his work (Arts and Gelissen, 2002), there are particular issues that limit its value for our purposes. The regime types do not best capture countrybased differences in elder care arrangements, and alternative groupings emerge when elder care (and child care) is made more central (Anttonen and Sipila, 1996; Bettio et al., 1998; Bettio and Plantenga, 2004). Moreover, the link between familial care and decommodification no longer holds in the context of arrangements where family members may be paid directly or indirectly by the state for care-giving work (Ungerson, 1995). In addition, the voluntary sector, which is neither market nor state, is completely absent from consideration. Similarly, migrant labour plays no role in the typology, and, whatever apparent concessions are made to feminist critiques, gender too remains marginal. As our outline of arrangements in Italy and the Netherlands demonstrates, elder care could not be understood without considering these three.

5.4 Esping-Andersen allocates both Italy and the Netherlands to the conservative welfare regime, given the centrality of familialism. Yet he also admits that both countries are problematic in not really fitting his typology. The Netherlands '... remains a Janus-headed welfare regime, combining both social democratic and conservative attributes' (1999: 88). With its strong universalism, comprehensive coverage and generous de-commodifying benefits, the Netherlands approximates social democracy. But in its 'sustained inattention to social services', it 'emerges as a prototype of Catholic familialism', and he explains generosity in income maintenance as an 'expression of pervasive male bread-winner assumption' (ibid). In the case of Italy, the suggestion of a Mediterranean regime is refused on the basis of complex statistical calculation and dispute over appropriate measures, in other words by technical rather than substantive argumentation, although the door appears open for future revision. From our perspective, these are serious deficiencies since we want to show that familial forms of care are neither homogeneous nor self-explanatory. Further, our aim is to explore how familial care in the two countries relates, differently in each case, to other sources of provision, as well to forms of paid and unpaid care.

5.5 A more targeted analysis of care work, though on an exploratory and far smaller scale, is suggested by the recent qualitative research of Yeandle and Ungerson (2003), and Ungerson (2006). They contrast the work relations associated with differing 'cash for care' schemes where care recipients receive cash to directly employ their carers (which may include spouses and relatives) in five European countries. They investigate how variations in the formal regulation and non-regulation of such work (for example whether 
relatives or those without formal training but with many years experience are eligible to be employees) produce differing work and emotional relations, creating hybrids of contract and affect. This framework is highly suggestive in differentiating between the relations of care work, from friendship to labour contract, that emerge from different regulations for both the delivery of care (standards and credentials) and the management of care as employment (social rights, taxes etc.). It also captures the degree of professionalisation of carers and their place within the formal or informal economy, and the state, the voluntary sector, the market or the family. However, it does not readily allow us to see interconnections between different forms of work which are the focus of our interest here.

5.6 Another fruitful approach for thinking about the organisation of care work, is provided by Mingione (1991). More centrally located in the sociology of work, he distinguishes differing dimensions of employment relations, understood as being on a continuum rather than dichotomous. For our purposes, this has the potential to facilitate an open and flexible perspective on work relations as combining a multiplicity of dimensions, which also permits paid employment and unpaid work to be encompassed within same analytical frame. In Table 1 we have adapted Mingione's dimensions (formal-informal; monetary-nonmonetary; legal-illegal-not provided for by law; and public-private) so as to apply them to the relations of care work. This allows us to perceive different socio-economic modes of work in relation to one another along key dimensions of differentiation. For instance, at one end of the spectrum, we can position formal employment in a residential facility as unambiguously formal, monetary, legal and public. At the other end, unpaid care work conducted within the home in relations of love or obligation can be unambiguously located as informal, non-monetary, not provided for by law. The extent to which it is purely private is, however, contested given the construction of the public/private divide through legal and policy measures. Indeed, as is already evident, different forms of unpaid work are produced by different welfare state arrangements. Aside from the cases at either end of the spectrum, locating other forms of care work along these dimensions becomes problematic since the dimensions do not operate separately 'in parallel' to one another. They are cross-cutting and in simultaneous relation to each other. To be used in practice, and to help capture change over time, the mappings would need to be situated in an organisational or institutional context.

Table 1. Socio-economic modes of care work

\begin{tabular}{|l|l|l|l|l|}
\hline formal & legal & monetary & public & Form of provision \\
\hline
\end{tabular}

Developed from Enzo Mingione (1991, Table 2.1, p80). Two categories from the column of 'forms of provision' are deleted from Mingione as non-relevant to care (criminal activities and self-provisioning); his category of reciprocal and voluntary unpaid activities is separated into two.

5.7 Our analysis of interactions between different socio-economic modes of care work is informed by these approaches. Our aim is to contribute to a framework that distinguishes between differing kinds of interconnection linking the activities of work, and whose application would extend to other fields and to the wider aims of the overall research programme. The conceptual schema of the 'total social organisation of labour', on which the present research builds, highlights relationality, configurations, and dynamic interdependence and interaction between different socio-economic modes. Since the relation between modes is likely to affect what goes internally within each (and vice versa) it is important to consider not only the internal 'workings' of each mode but also what goes on between them. Change within one may well alter what occurs in another, as well as the relationship between them. An example would be the interlinked changes between the commodity sector and household economy consequent on the introduction of mass production during the inter-war period, which transformed women's paid employment and household labour. 
The 'new industries' produced a range of goods (consumer durables, ready-made food and clothing) specifically aimed at household consumption, and recruited to factory employment hundreds of thousands of women who, in an earlier generation, might have worked as unpaid homemakers or paid domestic servants (Glucksmann, 1990). Focusing on these interconnections throws into perspective the distribution between paid and unpaid work, their changing proportions, and intersection.

5.8 We now consider the connections between the different socio-economic forms of care provision and the work relations associated with them in Italy and the Netherlands as a configuration. Figures $1 \mathrm{a}$ and $1 \mathrm{~b}$ attempt to represent diagrammatically the different configurations of elder care provision and resourcing in the Netherlands and Italy, illustrating the relationships between the four main forms of provision.

\section{CONFIGURATIONS OF CARE RESOURCING AND PROVISION}

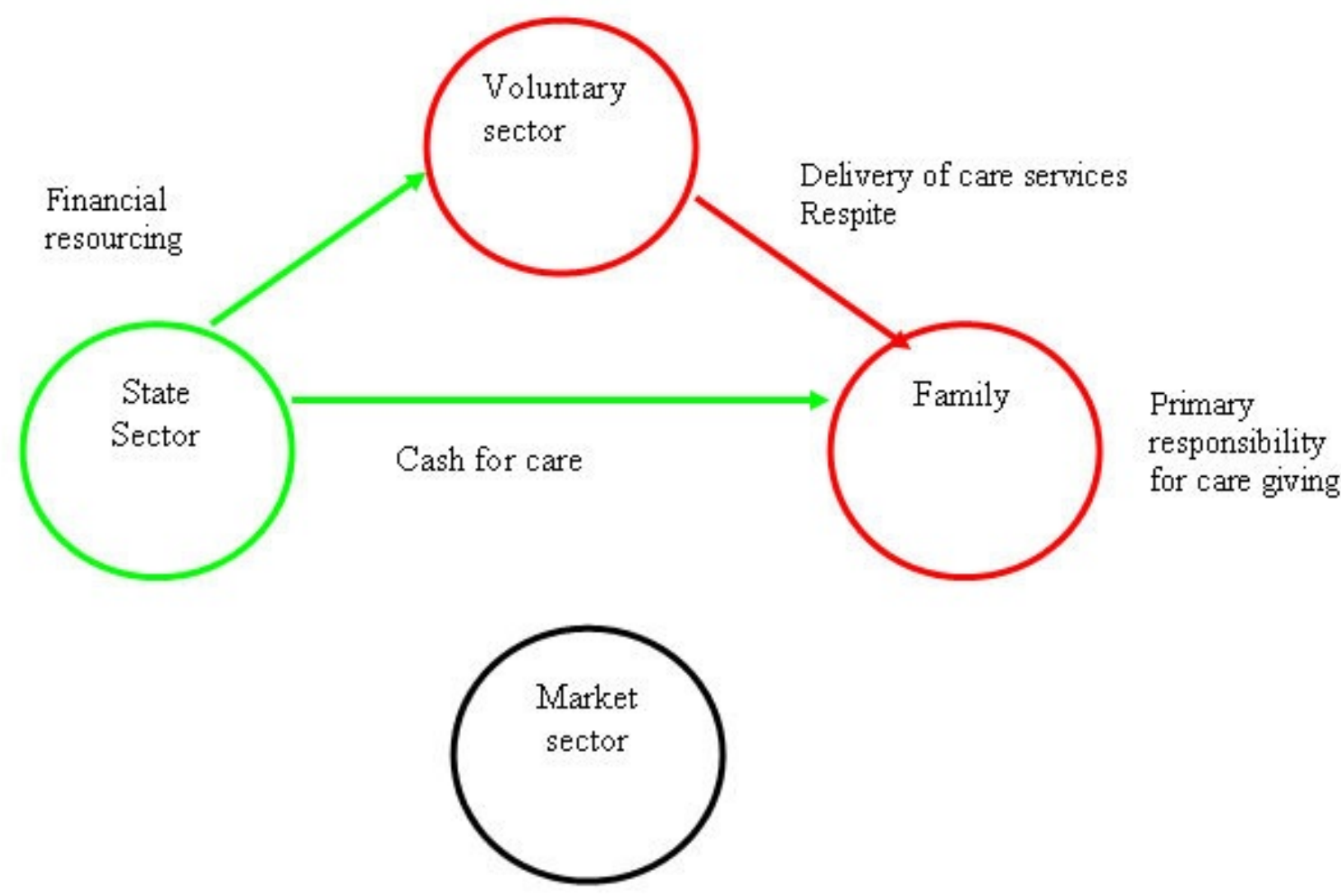

Fig 1a:

THE NETHERLANDS

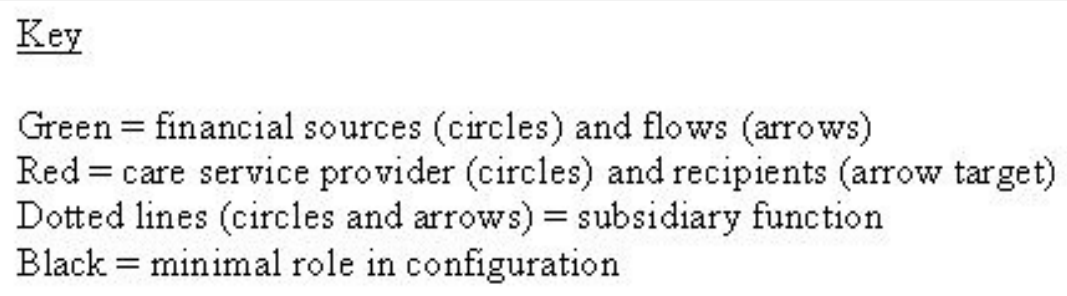

$\underline{\text { Key }}$

Green $=$ financial sources (circles) and flows (arrows)

Red = care service provider (circles) and recipients (arrow target)

Dotted lines (circles and arrows) $=$ subsidiary function

Black $=$ minimal role in configuration

5.9 In the Netherlands, family and relatives have primary responsibility for giving care, aided by the voluntary sector which provides respite primarily for carers. The public sector, national and local, provides modest financial resources directly to care recipients but funds the not-for-profit voluntary organisations almost in their entirety. Paid professional care workers and home helps are employed by this non-government sector, never directly by the state. The distinction between funding and delivery is thus key to the system. As yet, 
the market is of minimal significance. In sum, care work is provided by the family on an unaid basis, and by the voluntary sector on both a paid and unpaid basis (contracted out services employing care professionals and informal volunteers) which is in turn dependent on the state for its resources.

5.10 While the diagram is static, our research suggests that the trend of public policy is strongly in the direction of further reinforcing the responsibility of home and family for providing care. This is achieved in two ways. First, through de-institutionalisation and the provision of care in the receivers' own home. Second, through initiatives that financially 'support' informal carers. Respite services are the primary mechanism for this, provided by unpaid volunteers, with specialist nursing or medical back up by paid professionals. Overall then, the shifts are away from formal employment of carers in residential facilities provided by the state, to some formal employment of carers for the delivery of home-based care services and the greater provision of informal care, supported by cash payments (personal budgets).

5.11 The voluntary sector is connected to the other main forms of provision through assistance in residential facilities and in the home, and through the contracting of services from the state. Although at the moment the market for private care services is little developed this could be a future direction, especially for the welloff, as some voluntary sector organisations are considering developing additional for-profit services. Furthermore, with the proposed EC directive on market services, for-profit providers from other countries could well view the Netherlands as a potential untapped market.

5.12 What is significant in this scenario is the widespread support for volunteers and the effective contracting of non-medical care services by the state to the voluntary sector. The employment of professional carers may well be substituted to some extent with the unpaid labour of volunteers. In addition, the increase in the labour of informal family care is now financially supported through state-financed personal budgets paid directly to the recipients of care.

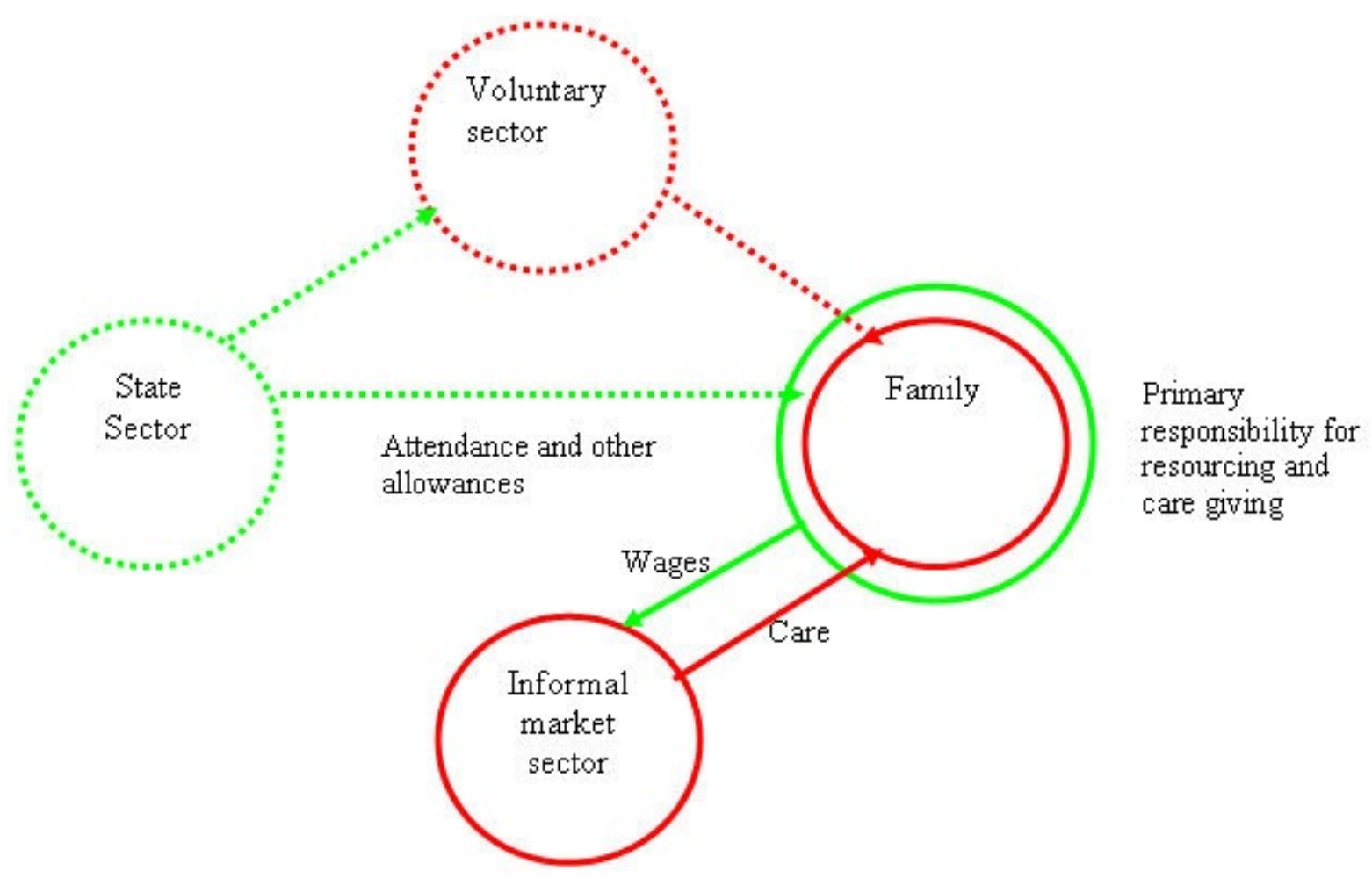

Fig 1b: ITALY

5.13 The configuration of elder care in Italy is mapped in Figure 1b. As in the Netherlands family care is the most significant form of provision, with spouses and daughters primarily and solely responsible for the direct labour of care. But the relation between informal care and other forms of provision differs considerably. Although the state has a minimal role in actually providing care, informal family labour is financially supported to some degree by the state. Pensions, disability payments, and attendance allowances, paid either to the recipient of care or to the provider of care herself, imply that informal labour is not necessarily and altogether 'unpaid'. Although the state funds the voluntary sector, which in turn supplies certain kinds of care to those in need, the scale of both these flows is limited, in no way on a par with the 
Netherlands. On the other hand, the market is far more present in the Italian configuration of care. Migrant household workers are recruited for the most part through informal market transactions made between individuals. Although the recent shift to paid migrant carers has freed family carers of some of the direct labour of care giving, they retain responsibility for managing not only the care itself but also the employment relationship with migrant carers. Family care thus remains dominant. Moreover, it is widely reported that Italian family members routinely perform basic personal care for relatives in residential facilities, taking in food and washing and dressing their relatives, indicating that the separation often assumed between formal and informal care may have little basis in practice (Fink, 2004: 33).

5.14 It is important to stress the close linkage between systems of care and the profile of women's employment in these countries. We know that the bulk of informal elder care is undertaken by middle aged women, and in Italy only 19.6 per cent of women aged 55-64 are in formal paid employment. Similarly, the preponderance of informal, unpaid and familial care in the Netherlands would be inexplicable without the 'the one-and a-half worker family model' where lower employment rates of older women (33.4 per cent of those aged 55-64) and the prevalence of part-time work (75\% of all women employed, cf $26 \%$ in Italy), make a sizeable proportion of older female cohorts potentially 'available' for care work. Whilst there are high levels of part-time employment in the Netherlands, women's employment in Italy is largely full-time (26\% parttime). The hours worked are comparable: an average 21 hours per week in the Netherlands, and 19 in Italy (Eurostat). However, there is no reason to assume this model will continue into the future, given that younger generations are already more likely to be employed full-time, and amongst the 55-64 age cohort, there has been a marked rise in employment over the past decade, from 17 to 33\% between 1993 and 2004 (ibid). Nor should the relation be seen as one-way. Having access only to informal care acts in itself a constraint on paid work. Indeed, Bettio and Platenga (2004:103) estimate the share of women working parttime because of care commitments as 11 per cent in the Netherlands and 1.9 in Italy (where part-time working is not so much the norm), while the share of female population 'non-active' because of care is 15.3 in the Netherlands and a massive 37 per cent in Italy. ${ }^{[14]}$

\section{Emdeddedness and differentiation: care, work and social relationships}

6.1 Although schematic, our analysis of configurations of care has some far-reaching implications, beyond elucidating the distribution of paid and unpaid work. These relate to another aim of the research to explore how the labour of care may be undifferentiated from or embedded in non-work activities and relationships such as domestic work or affective ties of love and support. The relational characteristics of each pattern sustain and/or are sustained by other dimensions of care, to which we now briefly turn.

6.2 Is care work? For many interviewees in both countries, work was defined as paid activity. In the Netherlands some had not thought of care as work at all, and were even surprised at the question. They maintained the separation between work and non-work by focusing on the altruistic and idealistic motives of volunteers in elder care, described by one volunteer co-ordinator as 'a motivation from inside'. At face value this may reflect the communitarian or solidaristic ethos of Dutch political culture (Glucksmann, 2006b). But it also suggests a cultural and political climate in which it is difficult to recognise care as an 'object and medium of power' (Sevenhuijsen, 2002: 25). In this context, it is interesting that altruism was fore-grounded even though the same respondent recognised the instrumentalism of people volunteering because the experience looks 'good on your CV'. Furthermore, volunteers in the Netherlands were frequently construed as not conducting 'real' work. Another interviewee (g) explained that 'they really have to know the boundary of informal care. They don't give injections or medicines, or do professional work' and this was despite a high proportion of volunteers actually being qualified nurses.

6.3 In Italy such a distinction between work and non-work remains relevant even in the case of paid carers. Sometimes the activity of migrant carers is described as 'minding', for instance if carers are on call within the domicile (especially at night) but may not be continuously actively engaged in caring activities. Even where the activity is paid care it may be positioned as not being real work - and this can be used as a justification for low wages: 'I mean, people want to argue... that they [migrant carers] should really not be paid so much... "Well, they don't really work. They're there to mind. They do nothing, they simply mind. They simply look with the eyes." ... So they say, "Well, it's 24 hours ... but, you know... most of the time you do nothing".' (Interview 2)

6.4 Care as kinship. In Italy, family care has incorporated externally supplied market-based care services through the employment of migrant carers, but this is done in order to sustain the practice and ideal of family care as delivered through love and personal connection. Whilst some of the actual labour of care has been displaced away from wives and daughters, they nevertheless remain responsible for managing the employment of carers. However, this situation is paradoxical: much of the labour of care is performed by a relative stranger in a cultural context which prizes kinship in care. This might help explain the widespread depictions of fictive familial ties and the caring qualities of the migrant women themselves. In a recent study of women migrants from Bulgaria and Hungary in Italy and the Netherlands, interviews with native Italian women exposed some of the characterisations of migrant women working in the field of care as 'naturally' gifted for such a role, and generally charitable in disposition, in contrast to their Italian counterparts (Passerini et al., 2007 forthcoming). Furthermore, distinctions were made between different migrant groupings, based on stereotypes which appear to be widespread. ${ }^{[15]}$ Of course, very real relations of 
affection (and abhorrence) certainly emerge. The boundaries between doing care work and feeling care are unstable and overlapping (Stone, 2000: 106), showing the permeability of labour, love and intimacy (Fink, 2004: 31).

6.5 In the Netherlands, the possibility of employing and paying relatives through personal budgets confronts the meanings associated with care - love and obligation, reciprocity and exchange - with the logic of the market. For some providers the 'contamination' of love and money is unsettling; whilst for others the gains in self-esteem and respect when 'life' becomes 'work' are welcome (Yeandle and Ungerson, 2003). In both settings, informal care-giving, particularly by daughters rather than partners, is more widespread amongst families with lower economic and social resources (de Roit, 2004: 314). And it is especially amongst such families that the discourse of 'direct care being best' is strongest.

6.6 Care for the person, the body, and the environment. The labour of care work may be indistinct from other work activities when it so absorbed within normal domestic activity that carers do not recognise themselves or the care work as such. Care is effectively 'hidden' amongst other activities (Bittman et al., 2004). In Italy the informality around the employment of migrant carers means there is often an overlap in the work of carers who take care of the environment of the elderly person (cleaning and maintenance), alongside care of the body (washing, dressing), and the person (conversation, company, and emotional support). Informal carers are responsible for all aspects of care with little or no support from external services. This scenario contrasts with the Netherlands where the division of labour between home care service workers, volunteers and informal carers is sharper. The greater part of state services in the Netherlands is aimed at the very needy. This means that those elderly persons who receive informal care in their homes from family or friends are, as a population, less needy than their counterparts in Italy who do not have the same access to state services.

6.7 Furthermore, bodywork has been recognised as a large part of care work (Twigg, 2000), and there are connections between different socio-economic modes of care work, cultural norms, and intimacy. Indeed, at a formal level, medical, social and personal care are configured very differently in different countries with sharp separations or closer overlaps. In the Netherlands there is more formal assistance for body work than in Italy where the intensity of home-based informal care work is greater. Culturally too, there is less expectation, especially in higher class contexts, that family members provide direct body or household care. As one interviewee comments: 'Even my mother is not expecting from the children that we take care of her physical things, her body things or of the household' (Interviewee c). Indeed, other research suggests that informal carers in the Netherlands rarely perform bodywork and personal hygiene (de Roit, 2004: 309).

6.8 Care as obligation. In addition to the personal and social dimensions of care on which we have focused, care also has a financial component, which may amount to a legally binding financial responsibility. In Italy, legal obligations extend to the third degree of kinship, although those most usually targeted (by local authorities) are spouses, sons and daughters, and sons and daughters-in-law (Polverini et al., 2004: 23). In the Netherlands, legal financial responsibility does not extend beyond the nuclear family. Nevertheless, there are interesting relationships in both cases between these different dimensions of care - personal, social, and financial. What is felt to be appropriate in terms of filial responsibility appears highly class and gender-related as well as culturally grounded. Filial responsibility takes the form of direct care at lower class levels and securing other forms of support amongst higher class families (de Roit, 2004: 356). And men tend to emphasise financial responsibility, leaving direct care to women. In both countries, filial responsibility is equated with care, but the content of what is deemed appropriate differs. In the Netherlands, people are more geared to gaining access to welfare state services, and in Italy more concerned with family involvement (ibid). In Italy in particular the sense of filial duty is ingrained: 'It is something that is psychologically very costly to give to your parents less than what they expect, and what you have thought all your life is right for them. Right?' (Interview 2)

6.9 Rights to care. Both effective rights to receive care, and people's understandings of them, may be expected to vary in accordance with different modes and configurations of provision (Glucksmann 2006b). For instance, in the case of state or public provision, rights are likely to be citizen-based, with citizens or qualifying residents entitled to receive care on the basis of legally instituted criteria. Rights to care by family and relatives have a quite different character: informal, rather than legally instituted, and dependent on goodwill, duty, or traditions of reciprocity. Alternatively, the rights to care that is purchased on the formal market may be more akin to consumer than to citizen rights in that care agencies are legally responsible in terms of trades descriptions or consumer protection (although this rarely extends to informal transactions). In voluntary care, rights and obligations are more amorphous, especially at the individual level, and no-one has the right to expect volunteers to care for them. Many voluntary care organisations, however, established precisely for this purpose, contract with the state or private persons to provide care. Furthermore, national variations in commonsense conceptions of rights are likely to accompany contrasting configurations of elder care with their different modalities and mixes of provision.

\section{Conclusion}

7.1 Our analysis suggests that the two countries investigated display contrasting configurations of elder care. Family care remains dominant in both, but in Italy it is 'supported' by informal and individually 
arranged market transactions in the context of weak collective (state) protection, and in the Netherlands by state-funded not-for-profit provision and by unpaid volunteers. In both countries, novel mixes of forms of care are evident which transcend the public/private, market/non-market and paid/unpaid distinctions, as well as the love/money/duty nexus. The resulting configurations elucidate the types, proportions and intersections between paid and unpaid forms of care work in the two countries. They also throw light on the differing ways in which care is undertaken (as obligation, kinship etc.), the kinds of work performed through different socioeconomic relationships, and people's experiences of them.

7.2 Our findings also reveal the need to refine or unpack our initial presentation of the four modes (market, state, voluntary and household). Formal market transactions are very different in nature from informal ones, and it is vital to distinguish between the two. An account of Italy highlighting the increasing amount of care work undertaken through the market would be misleading without specifying that this does not imply forprofit or large companies selling care services, and directly employing care workers (as in the UK and Sweden); rather, individual families purchase the services of individual migrants with whom they have made contact largely through informal networks. Similarly, the distinction between the funding and delivery of care is crucial, since in some countries the state might fund care but take no part in its actual delivery, while in others it is involved in provision and in the direct employment of care workers. Without this proviso, 'state' or 'public' provision cannot adequately capture what has been a key and long standing characteristic of the Dutch system in particular.

7.3 Turning to the voluntary or 'not-for-profit' sector, this also comprises diverse strands: professionals employed by formal institutions that are non-government and not-for-profit, informal volunteers co-ordinated by organisations that pay for expenses but not for labour, and individual informal volunteers. Further, our discussion has undoubtedly underplayed national specificity in family, household and kinship relations and structures which will have effects for patterns of residence and obligation. The same considerations apply to the meaning of elder care since it comprises different sets of components in different countries: financial, health, social, household and personal. Some make a rigid distinction between medical and personal care while others include household help and nursing under the same rubric. In short, what is implied by state, market and family is variable and differs nationally. Moreover, the content and salience of each of the four socio-economic modes varies in different countries, as well as their interrelation. Although sometimes posing problems for direct comparison, discovering these differences is a necessary element of an iterative research process.

7.4 Distinguishing between national configurations of care work, however, by no means amounts to explaining how and why they come to be as they are - an endeavour beyond our scope here. The discussion has touched briefly on the disparate socio-economies, 'welfare cultures' (Pfau-Effinger, 2005) and notions of care as a public good (Daly, 2002: 261) that underpin the contrasting policies for supporting care in Italy and the Netherlands. We have also referred to their demographic profile, household structures and familial relations, and, crucially, the pattern of women's employment characteristic of each country. Detailed and historical consideration of their political economies and broader social and cultural dynamics would also be invaluable to a full understanding. Properly explaining the prevailing configurations of care would involve analysing the interplay between and relative weight of all these dimensions. The specific character of elder care work in each country is to be understood, in part at least, as the complex outcome of a 'societal effect' (Maurice et al., 1986) which is in many respects, and inevitably, path-dependent (Pierson, 2000). Contemporary change is increasingly shaped by the encounter - or even confrontation between this 'long history' of each country and developments emerging at the European or EC level, such as policy moves towards 'the adult worker' model (Lewis and Giullari, 2005) or attempts at the creation of a common 'social Europe'.

7.5 All these considerations demonstrate the importance of conceiving of modes of provision not in the abstract, as market, state, voluntary sector or family, but rather as they are found, shaped by their particular societal contexts and relational configurations. This analytical perspective facilitates an understanding of the varying significance in different countries of the range of socio-economic modes of provision as well as the differentiation between paid and unpaid forms of care work. We hope also that this perspective has significance beyond the particular countries examined here, and beyond the empirical field of care work.

\section{Notes}

${ }^{1}$ The authors are indebted to the ESRC for support of 'Transformations of Work: New Frontiers, Shifting Boundaries, Changing Temporalities' research programme. The other probes are: ready-made food; new forms of intermediation including call-centres, and consumption 'work'. With regard to care work, the other countries in which we are conducting research are Sweden and the UK.

${ }^{2}$ See the 'Contrasting configurations of care work' section below for further elaboration of the configurational approach in analytical context.

${ }^{3}$ If, very broadly, care refers to the activity of looking after people who are not able to look after themselves 
(Daly, 2002: 252), it has been understood as labour and as love (Graham, 1991), as duty/obligation (e.g., Qureshi, 1996), and as a moral orientation, a way of being in the world (Tronto, 1993). For some the emotional dimension of the activity is foregrounded: 'care is the activity of attending to others and responding to their emotional needs' (Coltrane and Galt, 2000: 16); for others, work is more prominent, reflected in various terms, for instance 'care-giving work' (Waerness, 1984); 'people-centred work' (Thomas, 1993: 665), and 'care work' (e.g., Harrington Meyer, 2000).

${ }^{4}$ In the Netherlands, interviews were conducted in English, recorded and transcribed. In addition, documents not available in English were translated by a native Dutch academic. In Italy, interviews were largely conducted in Italian and in English in one case. They were either transcribed or full notes were written up from recordings.

${ }^{5} 40 \%$ of providers of informal help make use of support facilities: information, advice or emotional support $(40 \%)$; care attendance (17\%); and day care/activity centre $(10 \%) .70 \%$ of those who do not use any facilities say they have no need to do so (de Klerk, 2001).

6 In research on care providers, only $50 \%$ of respondents in the Netherlands recognised that ethnic minority elders have specific needs and access barriers (cf. 80\% in the UK) (Patel, 2004).

${ }^{7}$ From personal communications and brochures, publicity materials, and pamphlets collected at TAPS in zorg en welzijn (2005).

${ }^{8}$ Figures range from $5.1 \%$ in Spain to $31.8 \%$ in Finland (European foundation for the improvement of living and working conditions, 2004).

9 Data are from "Care Work in Europe" drawing on European Labour Force Survey and New Cronos Database (tables available at: http://144.82.35.228/carework/uk/index.htm).

${ }^{10}$ This compares with $86 \%$ in 1992 . The figure is also high in comparison to other EU countries where the proportion is between 85 and $92 \%$ female, according to European Labour Force Survey data. See Care Work in Europe project website <http://144.82.31.4/care work/uk/index.htm>. Other countries included in this analysis were the UK, Sweden, France, Germany, Denmark, and Spain.

${ }^{11}$ The last available figures (Caritas/Migrantes, 2004$)$ say that at the end of 2004 officially about 496,000
domestic workers worked in Italy, of whom $21 \%(104,000)$ come from the Ukraine, $16.4 \%(81,000)$ from
Romania, $9.5 \%(48,000)$ from the Philippines, $7.1 \%(34,000)$ from Poland, $6.4 \%(31,323)$ from Ecuador,
$5.7 \%(28,000)$ from Moldavia, and $5.1 \%(21,000)$ from Peru. The total officially estimated migrant population
is 2.5 million (Bettio et al., forthcoming). Trends in the use of migrant labour for elder care are also
confirmed in interviews (e.g., $3,4,5,18-20$ April 2005$)$.

${ }^{12}$ In Germany, Japan, UK and USA, the proportion is 5\%; in Canada, 6\%; in Australia, Belgium and France, 6.5\%; and in Sweden, 9\% (de Roit, 2004: 47, fn6). Interestingly in instances where the costs have been lowered or local authority cash contributions increased, applications have increased very significantly.

${ }^{13}$ Disability pension (233 Euros per month, but 252 Euros in case of full blindness) is means-tested, and paid by the State to the elderly; attendance allowance ( 430 Euros, but 670 Euros in case of blindness) is non-means-tested, paid by the State to fully disabled elderly only; care allowance (amount varies) is usually means-tested, paid by some (not all) local authorities (Municipalities or Regions) to (usually) only fully disabled elderly or their family caregivers (and in a few cases also to non relatives).

${ }^{14}$ These figures include child and elder care. They are especially significant given Italy's very low birth rate.

${ }^{15}$ For instance, women from some Latin American countries, according to the interviewees, have 'sweet' temperaments making them good carers (and less good cleaners). These stereotypes are widely reported in other research (e.g., de Roit, 2004: 317).

\section{References}

ANTTONEN, A. and Sipila, J. (1996) 'European Social Care Services: Is it possible to identify models?', Journal of European Social Policy, Vol. 6, No. 2, pp. $87-100$.

ANXO, D., and Fagan, C. (2005) 'The family, the state and now the market - home care services for the elderly', in G. Bosch and S. Lehndorff (editors) Working in the service sector - a tale from different worlds . Oxford: Oxford University Press. Routledge studies in business organizations and networks, Vol. 32.

ARTS, W. and Gelissen, J. (2002) 'Three worlds of welfare capitalism or more? A state of-the-art report', Journal of European Social Policy, Vol. 12 No. 2, pp. 137 - 158. 
BETTIO, F. and Plantenga, J. (2004) 'Comparing Care Regimes in Europe', Feminist Economics, Vol. 10, No. 1, pp. $85-113$.

BETTIO, F. and Prechal, S. in collaboration with Bimonte, S. and Giorgi, S. (1998) Care in Europe, Joint Report of the 'Gender and Employment' and the 'Gender and Law' Groups of Experts, European Commission DG V/D/5.

BETTIO, F., Simonazzi, A. and Villa, P. (forthcoming) 'The "care drain" in the Mediterranean: Notes on the Italian Experience'.

BITTMAN, M., Fast, J. E., Fisher, K. and Thompson, C. (2004) 'Making the invisible visible - the life and time(s) of informal care-givers', in N. Folbre and M. Bittman (editors) Family Time: The social organisation of care. London and New York: Routledge.

CARITAS/MIGRANTES (2004) Dossier statistico immigrazione. Roma.

COLTRANE, S. and Galt, J. (2000) 'The history of men's caring', in M. Harrington Meyer (editor) Care work: Gender, labour and the welfare state. New York and London: Routledge.

DALY, M. (2002) 'Care as a good for social policy', Journal of Social Policy, Vol. 31, No. 2, pp. 251 - 270.

DE KLERK, M. M. Y. (editor) (2001), Report on the elderly 2001, Changes in living situation. The Hague: Social and Cultural Planning Office of the Netherlands.

DE ROIT, B. (2004) Welfare systems, welfare packaging and coping strategies of social risks: the case of elderly dependence in comparative perspective, PhD thesis, Department of Sociology, Milano-Bicocca and IEP, Paris.

ESPING-ANDERSEN, G. (1990) The three worlds of welfare capitalism. Princeton, N.J.: Princeton University Press.

ESPING-ANDERSEN, G. (1996) Welfare states in transition: national adaptations in global economies, London: Sage.

ESPING-ANDERSEN, G. (1999) Social foundations of postindustrial economies . Oxford: Oxford University Press.

EUROPEAN FOUNDATION FOR THE IMPROVEMENT OF LIVING AND WORKING CONDITIONS (2004)

Health and care in an enlarged Europe <http://www.eurofound.ie/publications/files/EF03107EN.pdf>

EUROSTAT, <http://epp.eurostat.cec.eu.int/>.

FINK, J. (editor) (2004) Care: Personal Lives and Social Policy, Bristol: Policy Press in association with The Open University.

GLUCKSMANN, M. (1990) Women Assemble: Women Workers and the 'New Industries' in Inter-war Britain. London: Routledge.

GLUCKSMANN, M. (2000) Cottons and Casuals: the Gendered Organisation of Labour in Time and Space. Durham: Sociologypress.

GLUCKSMANN, M. (2006a), 'Shifting boundaries and interconnections: extending the "total social organisation of labour"', in L. Pettinger, J. Parry, R. F. Taylor and M. Glucksmann (editors) A New Sociology of Work? Oxford and Malden, MA.: Blackwell Publishing/The Sociological Review (forthcoming).

GLUCKSMANN, M. (2006b), 'Developing an economic sociology of care and rights' in L. Morris (editor), Rights: Sociological Perspectives, London, Routledge.

GLUCKSMANN, Miriam, (1995), 'Why "Work"? Gender and the "total social organisation of labour"', Gender, Work and Organisation, Vol. 2, No. 2, pp. 63 - 75.

GRAHAM, H. (1991) 'The concept of caring in feminist research: the case of domestic service', Sociology, Vol. 25, No. 1, pp. 61 - 78.

HARRINGTON MEYER, M. (editor) (2000) Care work: Gender, labour and the welfare state. New York and London: Routledge.

KNIJN, T. (2000) 'Marketization and the struggling logics of (home) care in the Netherlands', in M. Harrington Meyer (editor) Care work: Gender, class and the welfare state. New York: Routledge.

LEWIS, J. and Giullari, S. (2005) 'The adult worker model family, gender equality and care: the search for new policy principles and the possibilities and problems of a capabilities approach', Economy and Society, 
Vol. 34, No. 1, pp. $76-104$.

LYON, D. (2006) 'The organisation of care work in Europe: Gender and migrant labour in the new economy', Indiana Journal of Global Legal Studies , Vol. 13, No. 1, pp. 207 - 224.

MAURICE, M. Sellier, F. and Silvestre, J.J. (1986) The Social Foundations of Industrial Power: a Comparison of France and Germany. Cambridge, Mass: MIT Press.

MINGIONE, E. (1991) Fragmented Societies, A sociology of economic life beyond the market paradigm . Oxford: Blackwell.

MORRIS, L. (2002) Managing migration: Civic stratification and migrants' rights . London: Routledge.

NITSCHE, B., Scholten, C. and Visser, G. (2004) Ageing and informal care, Netherlands Institute for Care and Welfare.

OECD (1996) 'Caring for frail elderly people. Policies in evolution,' Social Policy Studies, No. 19, Paris: OECD.

PASSERINI, L., Lyon, D., Capussotti, E. and Laliotou, I. (editors) (2007) Women migrants from East to West: Gender, mobility and belonging in contemporary Europe. Oxford: Berghahn Books (forthcoming).

PATEL, N. (2004) Summary Findings of the Minority Elderly Care (MEC) Project , PRIAE Research Briefing: http://www.priae.org/docs/MEC\%20European\%20Summary\%20Findings2.pdf

PESARESI, F. and Gori, C. (2005) 'L'assistenza agli anziani non autosufficienti in Europa', in C. Facchini (editor), Anziani e Sistemi di Wefare. Milano, FrancoAngeli.

PFAU-EFFINGER, B. (2005) 'Culture and Welfare State Policies: Reflections on a Complex Interrelation', Journal of Social Policy, Vol. 34, No. 1, pp. 3-20.

PIERSON, P. (2000) 'Three worlds of welfare research', Comparative Political Studies, Vol. 33, Nos. 6/7, pp. $791-821$.

POLVERINI, F. et al. (2004) National Background Report for Italy, EUROFAMCARE: http://www.uke.unihamburg.de/extern/eurofamcare/documents/nabare_italy_rc1_a5.pdf

QUATTRINI et al. (2003) Studi Europeo ESAW: la condizione dei carers familiari di persone anzione in Italia. 48 Congresso Nazionale Società Italiana di Gerontologia e Geriatria, Firenze, 27-31 ottobre.

QURESHI, H. (1996) 'Obligations and support within families', in A. Walker (editor) The new generational contract, intergenerational relations, old age and welfare, London: UCL Press.

SARACENO, C. and Naldini, M. (2001) Sociologia della famiglia. Bologna: II Mulino.

SCIORTINO, G. (2004) 'When domestic labour is not native labour: the interaction of immigration policy and the welfare regime in Italy', in A. Górny and P. Ruspini (editors) Migration in the new Europe, East-West Revisited. Basingstoke, Palgrave Macmillan.

SEVENHUIJSEN, S. (2002) 'Normative concepts in Dutch policies on work and care', in S. Bashevkin (editor) Women's work is never done, Comparative studies in care-giving, employment, and social policy reform. New York and London: Routledge.

STONE, D. (2000) 'Caring by the book', in M. Harrington Meyer (editor) Care work: Gender, class and the welfare state. New York: Routledge.

THOMAS, C. (1993) 'De-constructing concepts of care', Sociology, Vol. 27, No. 4, pp. 649 - 669.

TIMMERMANS, J. M. (2003) Mantelzorg, Over de hulp van en aan mantelzorgers . Den Haag: SCP (English Summary).

TRIFILETTI, R. (1998) 'Restructuring Social Care in Italy', in J. Lewis (editor), Gender, Social Care and Welfare State Restructuring in Europe. Aldershot: Ashgate.

TRONTO, J. C. (1993) Moral Boundaries, A political argument for an ethic of care . New York and London: Routledge.

TWIGG, J. (2000) Bathing - the Body and Community Care . London and New York: Routledge.

UNGERSON, C. (1995) 'Gender, Cash and informal care: European Perspectives and Dilemmas', Journal of Social Policy, Vol. 21, No. 1, pp. $31-52$.

UNGERSON, C. (2006) 'Care, work and feeling', in L. Pettinger, J. Parry, R. F. Taylor and M. Glucksmann 
(editors) A New Sociology of Work? Oxford and Malden, MA.: Blackwell Publishing/The Sociological Review.

UNITED NATIONS, 2002 <http://www.un.org/esa/population/publications/ageing/Graph.pdf>.

WAERNESS, K. (1984) 'Caring as women's work in the welfare state', in H. Holter (editor) Patriarchy in a Welfare Society. Norway: Universitetsforlaget.

YEANDLE, S. and Ungerson, U. (2003) 'Gender and paid care work in modern welfare states: issues of work-life balance', Paper to ESRC Future of Work International Symposium, London 23-4 June. 